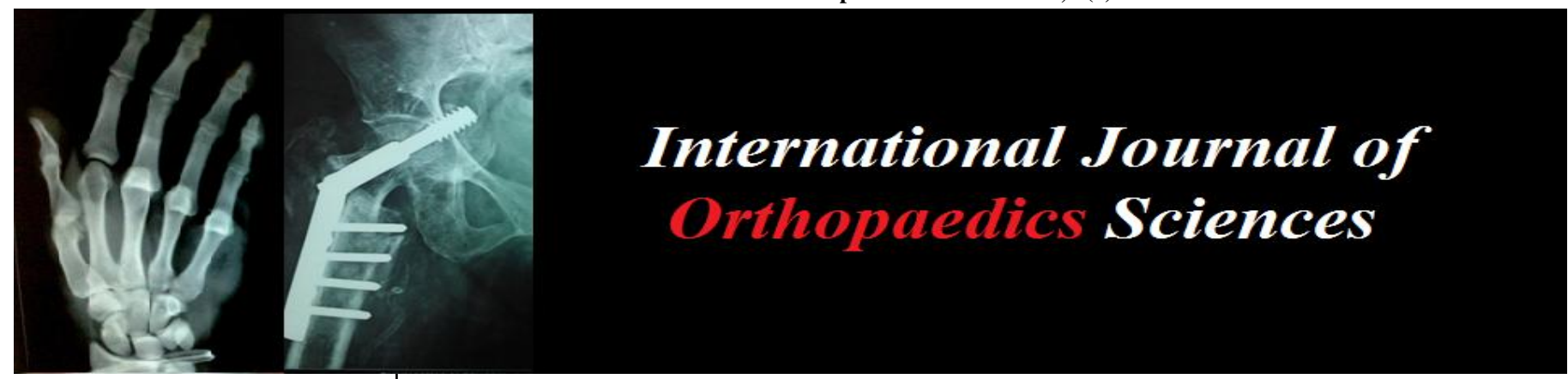

ISSN: $2395-1958$

IJOS 2018; 4(1): 576-580

(C) 2018 IJOS

www.orthopaper.com

Received: 02-11-2017

Accepted: 03-12-2017

Dr. Chirag V Thakka

Associate Professor,

GMERS, Gotri Medical College,

Vadodara, Gujarat, India

Dr. Mukesh S Dwivedi

Assistant Professor,

GMERS, Gotri Medical College,

Vadodara, Gujarat, India

Dr. Jitendra Rathva

Assistant Professor,

GMERS, Gotri Medical College,

Vadodara, Gujarat, India

Dr. Vikas Patel

Senior Resident,

GMERS, Gotri Medical College,

Vadodara, Gujarat, India

\section{Minimally invasive plate osteosynthesis in frkyman's type I to IV fractures of distal end radius: A study of 30 cases}

\author{
Dr. Chirag V Thakkar, Dr. Mukesh S Dwivedi, Dr. Jitendra Rathva and \\ Dr. Vikas Patel
}

DOI: https://doi.org/10.22271/ortho.2018.v4.i1i.82

\section{Abstract}

Introduction: Encouraged by the distinct advantages of minimally invasive plate osteosynthesis technique for treatment of peri-articular fractures of long bones, we have extended the concept for treatment of distal radius fractures. The aim of our study was to evaluate the clinical and functional outcome of MIPO technique for distal radius fractures.

Method: Thirty patients with isolated Frkyman's type I to IV fractures of distal radius were treated using minimally invasive approach of proximal vertical and distal transverse incision and fixed with volar locking plate and followed till six months post operatively. Final assessment was done using Mayo wrist scoring system at the end of six months.

Results: Based on Mayo wrist scoring system $73 \%$ had excellent results and $27 \%$ had good results. All patients could return to pre-injury work status by 8 weeks. There were no cases of neuro-vascular injury or joint stiffness and cosmetic acceptance of barely visible scar was very satisfactory.

Conclusion: Fixation of extra-articular distal radius fractures and minimally displaced, stable intraarticular fractures by using minimally invasive approach appears to be encouraging, reliable and easily reproducible by all.

Keywords: Stable fractures, pronator quadratus, minimally invasive

\section{Introduction}

Fractures of distal end radius are the most common injuries that affect upper limb injuries. $\mathrm{T}$ hey are common in all age groups with a slightly higher preponderance in elderly age group. Several treatment options ranging from close reduction and cast application, external fixation with or without $\mathrm{k}$-wire fixation, open reduction and internal fixation to more recently segment specific fixation have been done for these fractures. The best treatment option for these fractures is still debatable with advantages and disadvantages of each modality of treatment ${ }^{\text {[1- }}$ 4]. Close reduction and cast application has long been considered to be a good option for distal radius fractures in low demand patients. Some restriction of function has been an inevitable outcome of conservative treatment ${ }^{[2,3]}$. External fixation with or without $\mathrm{k}$-wire fixation has consistently shown better results in comminuted intra- articular fractures. However this modality of treatment is associated with higher incidence of pin site infection, occasional residual stiffness and nerve injury ${ }^{[5]}$. Conventional open reduction and internal fixation technique involves extensive soft tissue disruption and periosteal stripping which is probably associated with slightly higher infection rate, delayed union and joint stiffness ${ }^{[5,6]}$. The recent technique of minimally invasive plate osteo-synthesis has consistently given better results in fractures of proximal and distal femur, proximal and distal tibia ${ }^{[7,8]}$. This technique involves minimal injury to soft tissue envelope around the fracture site and no further damage to periosteal layer thereby preserving the vascularity of the fractured bone fragments ${ }^{[9]}$. The same concept has recently been expanded to treat fractures of upper extremity. Imatani et al. ${ }^{[10]}$ first reported 5 patients treated by MIPO technique by using two longitudinal incisions on palmar side of forearm. We performed MIPO using proximal vertical incision and distal transverse incision.

\section{Dr. Chirag V Thakkar}

Associate Professor,

GMERS, Gotri Medical College,

Vadodara, Gujarat, India 
Pronator quadratus muscle was not incised in our technique. Fixation was done using $2.7 \mathrm{~mm}$ locked anatomical locking plate. We reviewed 30 cases of volar locking plate using two incisions to assess the final outcome and complications of this technique at the end of six months.

Materials and methods: We conducted a prospective study of 30 cases of distal radius fractures treated at GMERS, Gotri medical college, Vadodara a tertiary care hospital, from Jan2014 to Jan -2017. Ethics committee approval and informed consent of all patients was taken before including them in our study.

Inclusion criteria: Age between 18 to 65 years. Closed isolated distal radius fracture (Frkyman's type I to IV).

Exclusion criteria: Open fractures. Other associated skeletal injuries. Intra-articular displaced fractures. Severe osteoporosis.

All patients were evaluated on outdoor basis in form of anteroposterior and lateral $\mathrm{x}$-rays of wrist joint. Patients with other associated injuries were excluded from the study. They were classified based on Frkyman's classification. Displaced intra-articular fractures and comminuted fractures were excluded from the study. Patients were explained the procedure and those who gave written consent for surgery were included in the study. They underwent pre-operative evaluation and assessment and once were fit for surgery posted for surgery. All the patients were operated under Brachial block in supine position under flouroscopic control.

Surgical procedure: Close reduction of the fracture was done and provisional reduction was held using one or two k-wires under flouroscopic guidance. A distal transverse incision of 2 cms was made two cms proximal to skin crease over the wrist. Subcutaneous tissue was cut in the line of incision. Flexor carpi radialis tendon was identified and retracted ulnarwards. Upper border of pronator quadratus muscle was identified by the transverse running muscle fibres. Sharp periosteum elevator was passed from below the upper border of pronator quadratus and extended proximally extra-periosteally. Another vertical incision was taken proximally along the radial border of flexor carpi radialis after deciding the length of the volar plate. Subcutaneous tissue and muscle were dissected by blunt dissection proximally till the volar surface of radius was clearly visible. A $2.7 \mathrm{~mm}$ locking volar plate of adequate size was passed from distal transverse incision beneath the pronator quadratus extra-periosteally and pushed proximally over the proximal vertical incision. Final position of plate was adjusted under flouroscopy and plate was fixed to bone using $2.7 \mathrm{~mm}$ screws. Initial provisonal $\mathrm{k}$-wires were removed and final fixation was confirmed under image intensifier. Both incisions were sutured and sterile padded dressing was applied. Post-operative x-rays were taken and limb kept elevated for next 24 hours. Wrist mobilization was started and patients were encouraged to do active physiotherapy as per pain tolerance. Stitches were removed on the $9^{\text {th }}$ post-operative day and subsequent follow-up was done at one month, three months and six months. At each follow-up radiological and clinical assessment was done and patients were evaluated by Mayo wrist scoring system at the end of six months.

\begin{tabular}{lr}
\hline Parameter & Score \\
\hline Pain & \\
No pain & 25 \\
Mild occasional & 20 \\
Moderate & 15 \\
Severe & 0 \\
Work status & \\
Regular job & 25 \\
Restricted job & 20 \\
Able to work but unemployed & 15 \\
Unable to work due to pain & 0 \\
Range of motion & \\
$>120^{\circ}$ & 25 \\
$100^{\circ}-119^{\circ}$ & 20 \\
$90^{\circ}-99^{\circ}$ & 15 \\
$60^{\circ}-89^{\circ}$ & 10 \\
$30^{\circ}-59^{\circ}$ & 5 \\
$0^{\circ}-29^{\circ}$ & 0 \\
Grip strength (\% of normal) & \\
$90-100$ & \\
$75-89$ & 25 \\
$50-74$ & 15 \\
$25-49$ & 10 \\
$0-24$ & 5 \\
\hline
\end{tabular}

Mayo wrist scoring system.

$\begin{array}{ll}\text { Results } & \\ \text { Excellent } & 90 \text { to } 100 \\ \text { Good } & 80 \text { to } 89 \\ \text { Fair } & 65 \text { to } 79 \\ \text { Poor } & <65\end{array}$

\section{Results}

A total of 30 patients were enrolled in the study from Jan2014 to Jan-2017 as per the inclusion and exclusion criteria. All of them underwent close reduction and minimally invasive plate osteosynthesis using $2.7 \mathrm{~mm}$ anatomical locking volar plate by proximal vertical incision and distal transverse incision under regional anaesthesia. 21 were male and 9 were female. 18 had fracture on right side and 12 had fracture on left side. All patients had indirect mode of injury in form of fall on outstretched hand. Average age was 40 years with a range of 19 to 65 years. Average admission-operation interval was 3 days with a range of 2 to 6 days. Average duration of post-operative stay was 3 days with a range of 2 to 7 days. All patients underwent suture removal at the end of 9 days. None of the patients developed superficial or deep infection in our subsequent follow-up. There was no case of intra-operative or post-operative neurological or vascular injury. No patient complained of operative scar tenderness or thickening by the end of six weeks. All the fractures united at an average duration of 6 weeks. There was no case of implant failure or irritation at the end of six months. No patient required implant removal and none came for the same in subsequent followups. All patients returned to pre-injury work status by the end of 8 weeks. Based on Mayo wrist score system we had excellent results in $22(73 \%)$ patients, good results in $8(27 \%)$ patients. None of them had fair or poor results. 


\section{Discussion}

With ever changing scenario in newer techniques and advancement in fixation methods of fractures, minimally invasive plate osteosynthesis has emerged as a clear choice for treating fractures. The balance has gradually tilted towards MIPO from conventional open reduction and internal fixation methods for several fractures over time. MIPO technique has been consistently proven to be safe and effective method in treating long bone fractures, particularly of proximal and distal tibia and femur fractures ${ }^{[11]}$. In this study we have extended the indication of MIPO in treatment of Frkyman's type I to IV fractures of distal radius by using a proximal vertical and distal transverse incision and fixing the fracture with $2.7 \mathrm{~mm}$ locking volar plate. We have evaluated the results with reference to radiological union and clinical and functional outcome at the end of six months.

Deep head of pronator quadratus acts as a dynamic stabilizer of the distal radio-ulnar joint ${ }^{[12,13]}$. It contributes $21 \%$ of the pronator strength of wrist joint ${ }^{[14]}$. Conventional ORIF sacrifices this stabilizer. According to Dangke et al. ${ }^{[15]}$ there is still controversy about the result of repair of pronator after ORIF. Armangil et al. ${ }^{[16]}$ in their study concluded that suturing of pronator after ORIF decreased the strength and endurance. Preserving the radial attachment of pronator could reduce the damage to blood supply around the fracture [17]. Our technique preserves the attachment of pronator over the distal radius.

Conventional open reduction and plating damages the pronator and can potentially lead to delayed healing, infection and joint stiffness due to extensive soft tissue stripping. Also this technique has reported the complication of median nerve injury ranging from $0 \%$ to $17 \%{ }^{[18]}$. For the same reason probably external fixation technique gave good functional outcome as it preserves the soft tissues. However the radiological outcome was better in ORIF than external fixator [18].

MIPO technique allows preservation of fracture haematoma which stimulates rapid bone healing. In our study all the fractures united by the end of 6 weeks. Early joint mobilization was probably possible due to preservation of pronator which decreased the chances of joint stiffness. Most of the patients could achieve full range of functional wrist movements by the end of four weeks. By the end of two months all patients had returned to their pre-injury work status. The cosmetic satisfaction of barely visible scar of surgery was of great comfort to most of the patients. None of the patients had pain and tenderness around the scar at six months follow-up. Mayo wrist score at the end of six months was excellent in $73 \%$ and good in $27 \%$.

$\mathrm{Xu}$ Ming et al. ${ }^{[18]}$ in their study concluded that minimally invasive approach and plate osteosynthesis of distal radius fractures with volar locking plate is a safe and effective means of fixation with radiological outcome comparable to those published in literature for standard volar locked plate.

Although this technique of fixation is not suitable for all types of distal radius fractures, but still it can be considered as one of the options in limited group of extra-articular fractures and stable minimally displaced intra-articular fractures. More research work is still needed with a larger sample size and longer follow-up and comparative studies are needed to conclusively establish the clear benefits of this method over conventional volar approach.

\section{Limitations of study}

We had a small sample size of 30 patients. Study did not include comminuted fractures and unstable fractures of distal end radius which also form a significant part of distal radius fractures. No comparative study has been done with other modalities of treatment of such fractures. Six month followup of patients seems to be too short to reach to a conclusion of long term result of this method of treatment.

\section{Conclusion}

Short to medium term results of minimally invasive plate osteosynthesis technique in distal radius fractures seem to be encouraging. This technique does not disturb the anatomy of pronator quadratus and it being extra-periosteal preserves the vascularity of fracture fragments. It allows better cosmetic acceptance with early mobilization and good functional recovery. However as compared to a longer learning curve of MIPO technique for other fractures this fracture seems to be much easier to learn and master it. Fixation of extra-articular fracture and minimally displaced, stable intra-articular fractures by using minimally invasive approach appears to be a reliable and reproducible method.

\section{Recommendation}

Based on our study we recommend MIPO techninque for Frykman's type I to IV fractures of distal radius due to better cosmetic and functional results.

\section{Conflict of interest}

The authors have no conflict of interest to declare.

\section{Funding}

This study is not supported by any grant whatsoever from any institute or organization or company.

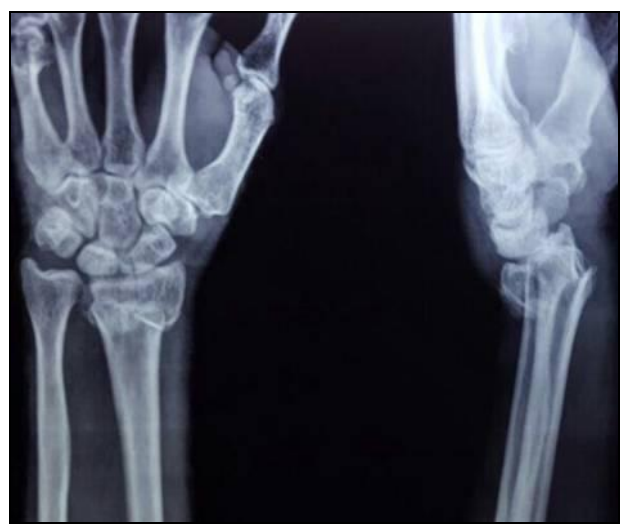

Pre-operative x-ray. Case- 21 .

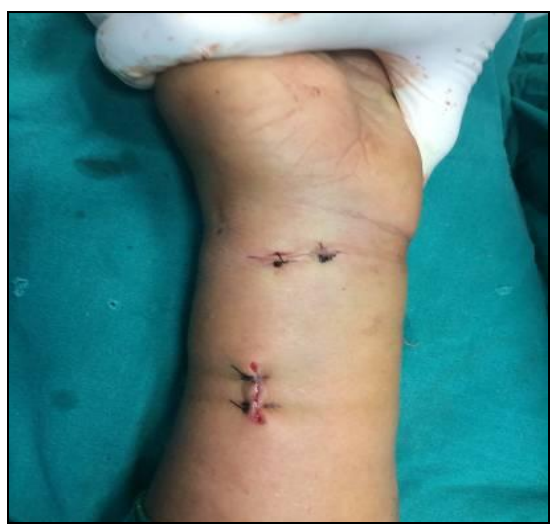

Vertical and transverse incision 


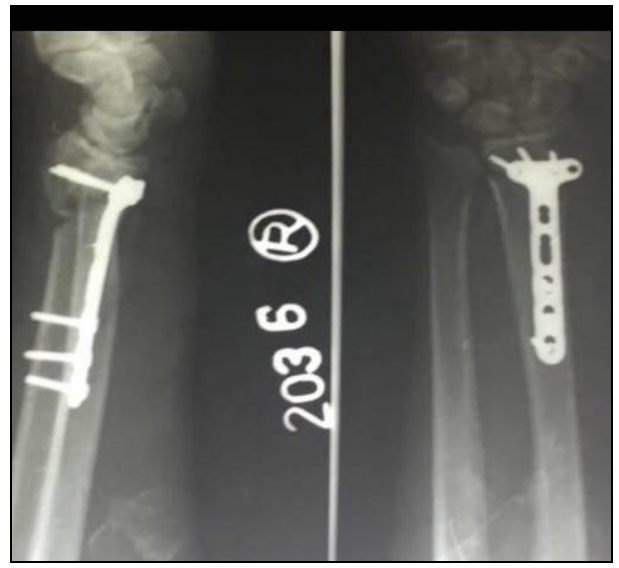

Post-operative x-ray.

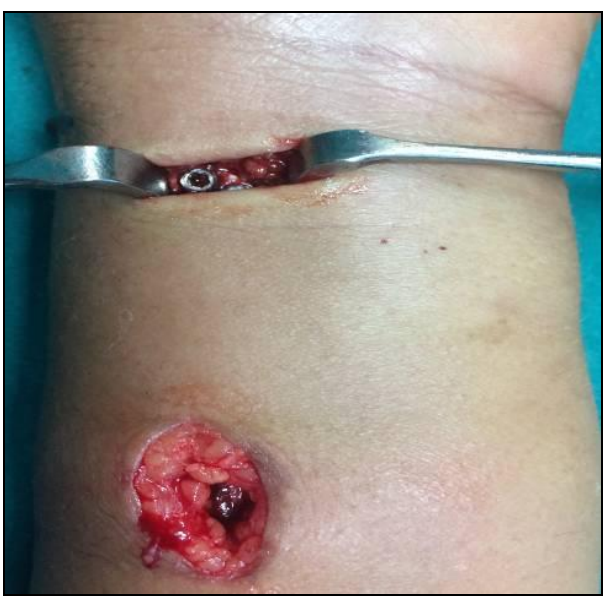

Intra-operative view.

\section{References}

1. Handoll HH, Madhok R. Surgical interventions for treating distal radial fractures in adults. In: Handoll $\mathrm{HH}$, editor. The Cochrane Database of Systematic Reviews [Internet]. Chichester, UK: John Wiley \& Sons, Ltd, 2003. [cited 2018 Jan 31]. CD003209. Available from: http://www.ncbi.nlm.nih.gov/pubmed/12917953

2. Cherubino P, Bini A, Marcolli D. Management of distal radius fractures: Treatment protocol and functional results. Injury [Internet]. [cited 2018 Jan 31] 2010; 41(11):1120-6. Available from:

http://linkinghub.elsevier.com/retrieve/pii/S00201383100 06716

3. Westphal T, Piatek S, Halm J-P, Schubert S, Winckler S. Outcome of surgically treated intraarticular calcaneus fractures-SF-36 compared with AOFAS and MFS. Acta Orthop Scand [Internet]. [cited 2017 Dec 26]; 2004; 75(6):750-5. Available from:

http://www.ncbi.nlm.nih.gov/pubmed/15762267

4. Kehr P. Robert W. Bucholz, Charles M. Court-Brown, James D. Heckman, Paul Tornetta III (Eds.). Margaret M. McQueen, William M. Ricci (Ass. Eds.): Rockwood and Green's fractures in adults, 7th edn. Eur J Orthop Surg Traumatol [Internet]. [cited 2018 Jan 31] 2012; 22(7):631-631. Available from: http://link.springer.com/10.1007/s00590-011-0927-2

5. Kapoor H, Agarwal A, Dhaon BK. Displaced intraarticular fractures of distal radius: a comparative evaluation of results following closed reduction, external fixation and open reduction with internal fixation. Injury [Internet]. [cited 2018 Jan 31] 2000; 31(2):75-9. Available from:

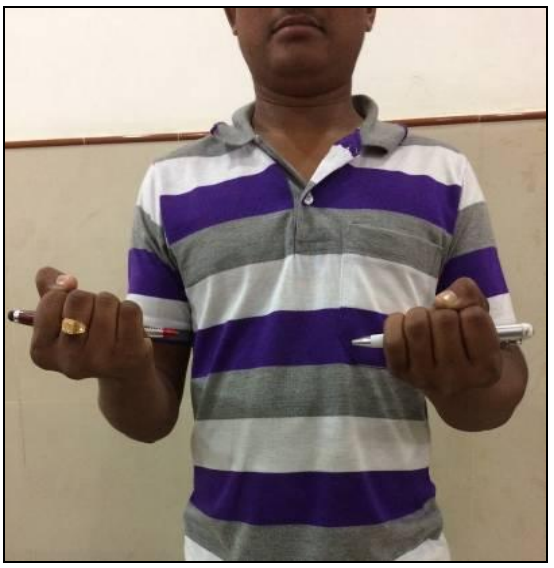

Supination at 1 month post-op.

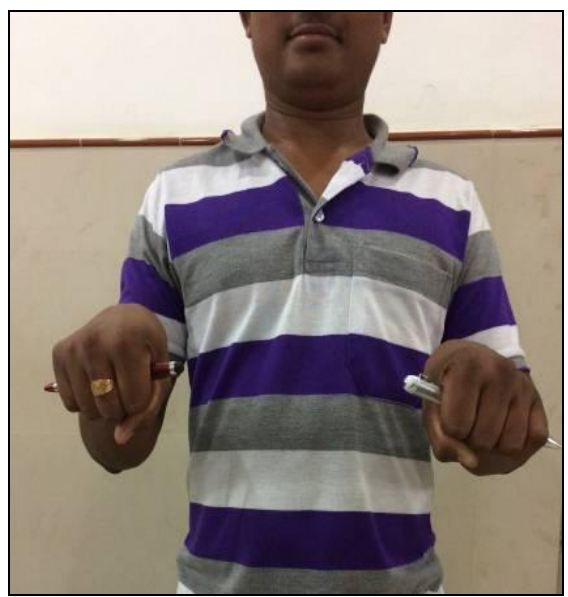

Pronation at 1 month post-op.

http://www.ncbi.nlm.nih.gov/pubmed/10748808

6. Kreder HJ, Hanel DP, Agel J, Mckee M, Schemitsch EH, Trumble TE et al. Indirect reduction and percutaneous fixation versus open reduction and internal fixation for displaced intra-articular fractures of the distal radius. $\mathbf{J}$ Bone Jt Surg [Br] [Internet]. [cited 2018 Jan 31] 2005; 8787(6):829-36. Available from: https://pdfs.semanticscholar.org/c268/571fdb239137f611 74725bf31d16b3d9b30d.pdf

7. Apivatthakakul T, Chiewcharntanakit S. Minimally invasive plate osteosynthesis (MIPO) in the treatment of the femoral shaft fracture where intramedullary nailing is not indicated. Int Orthop [Internet]. [cited 2018 Jan 31] 2009; 33(4):1119-26. Available from: http://link.springer.com/10.1007/s00264-008-0603-2

8. Collinge C, Kuper M, Larson K, Protzman R. Minimally invasive plating of high-energy metaphyseal distal tibia fractures. J Orthop Trauma [Internet]. 2007 Jul [cited Jan 31] 2018; 21(6):355-61. Available from: http://content.wkhealth.com/linkback/openurl?sid=WKP TLP:landingpage\&an=00005131-200707000-00001

9. Helfet DL, Shonnard PY, Levine D, Borrelli J. Minimally invasive plate osteosynthesis of distal fractures of the tibia. Injury [Internet]. [cited 2018 Jan 31] 1997; 28;1:A42-7-8. Available from: http://www.ncbi.nlm.nih.gov/pubmed/10897286

10. Imatani J, Noda $T$, Morito $Y$, Sato $T$, Hashizume $H$, Inoue $\mathrm{H}$. Minimally invasive plate osteosynthesis for comminuted fractures of the metaphysis of the radius. $\mathbf{J}$ Hand Surg Br [Internet]. [cited 2018 Jan 31] 2005; 30(2):220-5. Available from: http://www.ncbi.nlm.nih.gov/pubmed/15757779 
11. Gutierrez Olivera N, Ruchelli L, Iglesias S, Capomassi M, Allende C. Minimally invasive plate osteosynthesis in distal radius fractures with metaphyseal extension: A series of 13 cases. Chir Main [Internet]. [cited 2018 Jan 31]. 2015; 34(5):227-33. Available from: http://www.ncbi.nlm.nih.gov/pubmed/26359856

12. Stuart PR. Pronator quadratus revisited. J Hand Surg Br [Internet]. [cited 2018 Jan 31] 1996; 21(6):714-22. Available from: http://www.ncbi.nlm.nih.gov/pubmed/8982912

13. Gordon KD, Dunning CE, Johnson JA, King GJW. Influence of the pronator quadratus and supinator muscle load on DRUJ stability. J Hand Surg Am [Internet]. Nov [cited 2018 Jan 31] 2003; 28(6):943-50. Available from: http://www.ncbi.nlm.nih.gov/pubmed/14642509

14. Rey P-B, Rochet S, Loisel F, Obert L. Technical note: How to spare the pronator quadratus during MIPO of distal radius fractures by using a mini-volar plate. Chir Main [Internet]. [cited 2018 Jan 31] 2014; 33(2):95-9. Available from: http://www.ncbi.nlm.nih.gov/pubmed/24629441

15. Li D, Wang B, Li X, Cao G, Lv F. Clinical comparative observation of volar plate use for preserving pronator quadratus in distal radius fracture treatment. Biomed Res [Internet]. [cited 2018 Jan 31] 27(4). Available from: http://www.alliedacademies.org/articles/clinicalcomparative-observation-of-volar-plate-use-forpreserving-pronator-quadratus-in-distal-radius-fracturetreatment.html

16. Armangil M, Bezirgan U, Başarır K, Bilen G, Demirtaş $\mathrm{M}$, Bilgin SS. The pronator quadratus muscle after plating of distal radius fractures: is the muscle still working? Eur J Orthop Surg Traumatol [Internet]. Apr 23 [cited 2018 Jan 31] 2014; 24(3):335-9. Available from: http://www.ncbi.nlm.nih.gov/pubmed/23435787

17. Rath S, Hung LK, Leung PC. Vascular anatomy of the pronator quadratus muscle-bone flap: a justification for its use with a distally based blood supply. J Hand Surg Am [Internet]. [cited 2018 Jan 31] 1990; 15(4):630-6. Available from: http://www.ncbi.nlm.nih.gov/pubmed/2380528

18. Wei X, Sun Z, Rui Y, Song X. Minimally invasive plate osteosynthesis for distal radius fractures. Indian J Orthop [Internet]. [cited 2018 Jan 31] 2014; 48(1). Available from:

http://www.ijoonline.com/temp/IndianJOrthop481203508627_094446.pdf 